\title{
Influência do momento de colheita sobre a deterioração pós-colheita em folhas de taioba.
}

\author{
Rivelino Seganfredo; Fernando Luis Finger; Raimundo S. Barros; Paulo R. Mosquim \\ UFV, 36.571-000, Viçosa, MG; Email: ffinger@mail.ufv.br
}

\begin{abstract}
RESUMO
O presente experimento teve por objetivo avaliar a influência do momento de colheita sobre a vida de prateleira de folhas de taioba (Xanthosoma sagittifolium) clone Mangarito Roxo. As folhas foram colhidas 5; 8 e 15 dias após a completa expansão do limbo foliar, para determinação de largura, comprimento, teores de oxalato de cálcio, açúcares solúveis totais, amido e clorofila total. As folhas foram armazenadas no escuro, à temperatura de $25^{\circ} \mathrm{C}$ e umidade relativa de $95 \%$, até o completo amarelecimento do limbo. Procederam-se, no intervalo, determinações físicas e químicas. Folhas colhidas aos 5; 8 e 15 dias tiveram comprimento e largura semelhantes. Os teores de oxalato de cálcio decresceram significativamente com a idade. Folhas mais velhas exibiram menor teor de açúcares solúveis totais e de amido no momento da colheita. Na pós-colheita, ocorreu degradação dos açúcares e da clorofila total em folhas procedentes das três épocas de colheita. Folhas colhidas 5 e 8 dias após a completa expansão do limbo foram descartadas, por excessivo amarelecimento, 96 horas após a colheita, e aquelas colhidas com 15 dias foram descartadas após 72 horas. A taxa de perda de matéria fresca foi superior em folhas colhidas com 5 e 8 dias, em relação às colhidas com 15 dias de idade.
\end{abstract}

Palavras-chave: Xanthosoma sagittifolium, açúcares solúveis, amido, clorofila, oxalato.

\begin{abstract}
Influence of the maturity stage at harvest on shelf-life of tannia leafs.

The influence of leaf maturity at harvest was evaluated to obtain the post-harvest quality and deterioration of tannia (Xanthosoma sagittifolium) leaves. Leaves were harvested $5 ; 8$, and 15 days after unfolding and stored in the dark until yellowing. At harvest, the leaves showed similar width and length. Older leaves exhibited lower calcium oxalate content. Soluble sugars and starch were significantly decreased with the leaf age at harvest. Throughout postharvest ageing soluble sugars and chlorophyll contents showed trends of continued degradation in the leaves harvested in the three stages. Deterioration was evident at 96 hours in the leaves harvested 5 and 8 days after unfolding, and 72 hours in the leaves harvested 15 days after unfolding. The rate of fresh matter loss was higher in leaves harvested 5 and 8 days than those harvested 15 days after unfolding.
\end{abstract}

Keywords: Xanthosoma sagittifolium, soluble sugars, starch, chlorophyll, oxalate.

(Aceito para publicação em 16 de outubro de 2.001)

\begin{abstract}
$\mathrm{A}$ taioba (Xanthosoma sagittifolium) é uma hortaliça folhosa originária das regiões tropicais da América do Sul, que se desenvolve principalmente em regiões de clima tropical e subtropical. Seu cultivo é bastante difundido, sendo intensamente cultivada e consumida em países da América Central, África e Ásia. No Brasil, apesar dos incentivos governamentais nas décadas de 40 e 50 (Bondar, 1954), o cultivo de taioba é pequeno, sendo considerada ainda uma olerícola de fundo de quintal. A taioba é consumida como folha, principalmente nos Estados da Bahia, Minas Gerais, Rio de Janeiro e Espírito Santo. Os rizomas desta planta também são comestíveis. Na África e na Ásia é comum o seu consumo (Rubatzky \& Yamaguchi, 1997). No Brasil, a utilização dos rizomas na alimentação humana é insignificante.

De acordo com consumidores, em condições ambientais normais, as folhas
\end{abstract}

sofrem alterações visuais (amarelecimento e murchamento) e de sabor, poucas horas após destacadas da planta, limitando seu período de exposição e armazenamento no comércio. É possível que essas variações sejam devidas à idade e tamanho da folha no momento da colheita. Como ocorre com outras folhosas, a perda do valor comercial do produto fresco deve-se à murcha e perda da cor verde, que é caracterizada pela brusca queda nos teores de clorofila, redução da atividade fotossintética e concomitante diminuição dos níveis de carboidratos (Kays, 1991). A taxa de deterioração é função da temperatura, composição e umidade do ar, luz e de fatores internos, como níveis de hormônios e estádio de desenvolvimento na colheita (Wills et al., 1998).

Outro fator limitante para o consumo de folhas e rizomas de taioba é a ocorrência de cristais de oxalato de cál- cio nos tecidos, que provocam amargor e adstringência na boca e garganta (Hussain et al., 1984; Neto, 1995). Na literatura não há relatos sobre variações nos teores de oxalato de cálcio na folhas durante o seu desenvolvimento.

Este trabalho teve como objetivo estudar a influência do estado de maturidade das folhas durante a colheita sobre sua qualidade e curso da deterioração, quando armazenadas em condições de temperatura ambiente.

\section{MATERIAL E MÉTODOS}

Folhas de taioba (Xanthosoma sagittifolium), clone Mangarito Roxo, foram colhidas na horta da Universidade Federal de Viçosa, no período da manhã em três idades distintas, aos 5 (estádio I), 8 (estádio II) e 15 dias (estádio III) após a completa expansão do 
Tabela 1. Características das folhas de taioba colhidas aos 5; 8 e 15 dias após a completa expansão dos respectivos limbos, Viçosa, UFV, 1998.

\begin{tabular}{lccccc}
\hline Colheita (dias) & $\begin{array}{c}\text { Comprimento } \\
\text { (cm) }\end{array}$ & Largura (cm) & $\begin{array}{c}\text { Oxalato de Ca } \\
\text { (mg/g MS) }\end{array}$ & $\begin{array}{c}\text { Açúcares totais } \\
\text { (mg/g MS) }\end{array}$ & $\begin{array}{c}\text { Amido } \\
\text { (mg/g MS) }\end{array}$ \\
\hline 5 & $25,2 \mathrm{a}$ & $1,2 \mathrm{a}$ & $38,0 \mathrm{a}$ & $95,0 \mathrm{a}$ & $175,0 \mathrm{a}$ \\
8 & $27,1 \mathrm{a}$ & $1,4 \mathrm{a}$ & $34,0 \mathrm{~b}$ & $91,0 \mathrm{~b}$ & $55,0 \mathrm{~b}$ \\
15 & $27,2 \mathrm{a}$ & $1,7 \mathrm{a}$ & $31,0 \mathrm{c}$ & $61,0 \mathrm{c}$ & $25,0 \mathrm{C}$ \\
\hline
\end{tabular}

Médias seguidas de mesma letra nas coluna não diferem entre si, a 5\% de probabilidade, pelo teste-t.

limbo foliar (considerados como idade das folhas). A temperatura média durante o crescimento das folhas foi $23,6^{\circ} \mathrm{C} \mathrm{e}$ umidade relativa $80,5 \%$. Após colhidas, as folhas foram transportadas para o laboratório e armazenadas em câmara escura com temperatura de $25 \pm 2^{\circ} \mathrm{C}$ e umidade relativa de $95 \pm 2 \%$, até completo amarelecimento do limbo foliar.

O tamanho do limbo foliar foi determinado pela medição de seu comprimento e largura. O comprimento foi obtido pela distância entre o ápice do limbo das folhas e o ponto de inserção do pecíolo. A largura foi tomada como a soma das distâncias entre a inserção do pecíolo e as extremidades das duas nervuras principais laterais (Chapman, 1964). O oxalato de cálcio das folhas foi extraído e quantificado segundo Iwuoha \& Kalu (1995) e o cálcio foi determinado por espectrofotometria de absorção atômica, usando-se cloreto de cálcio como padrão. Os pigmentos do limbo foliar foram extraídos com acetona $80 \%$, em cerca de $2 \mathrm{~g}$ de tecido, e o teor de clorofila total segundo Arnon (1949). Os açúcares totais foram extraídos de $2 \mathrm{~g}$ de folha com etanol $80 \%$ fervente e quantificados por reação com antrona (McCready et al., 1950). O amido foi extraído do resíduo proveniente da extração dos açúcares solúveis, hidrolisado com ácido perclórico 30\% e estimado também por reação com antrona. A perda de matéria fresca foi avaliada diariamente e a matéria seca foi determinada por secagem das folhas em estufa com ventilação forçada, a $70^{\circ} \mathrm{C}$. Foram consideradas inaceitáveis para a comercialização folhas que apresentassem $75 \%$ da área foliar com coloração verde-claro e $25 \%$ com amarela.

$\mathrm{O}$ delineamento experimental foi inteiramente casualizado, com 10 repetições para determinar a perda de matéria fresca (cada folha como uma unidade

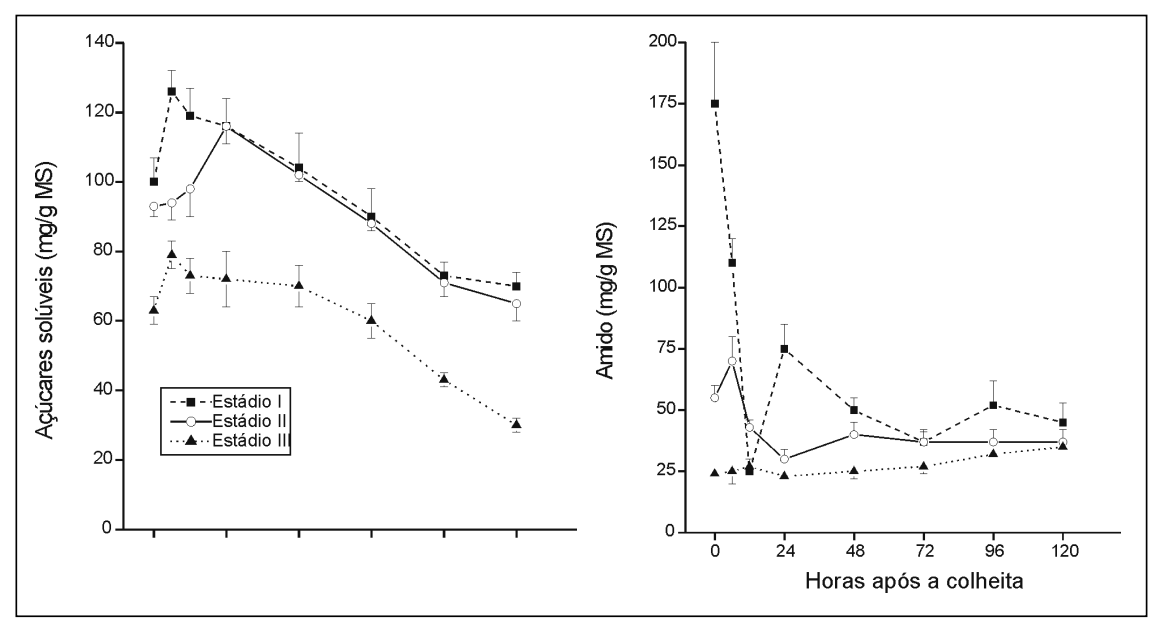

Figura 1. Alterações nos teores de açúcares solúveis total e amido em folhas de taioba colhidas 5 (estádio I), 8 (estádio II) e 15 dias (estádio III) após a completa expansão dos respectivos limbos, e armazenadas a $25^{\circ} \mathrm{C}$ e $95 \%$ de umidade relativa. Viçosa, UFV, 1998.

experimental) e cinco repetições para as demais determinações. Os dados foram submetidos à análise de variância e as médias foram comparadas pelo teste-t.

\section{RESULTADOS E DISCUSSÃO}

Folhas colhidas 5; 8 e 15 dias após a completa expansão dos limbos exibiram comprimento e largura semelhantes, indicando que a maior parte do crescimento ocorreu antes daquele evento (Tabela 1). Os níveis de oxalato de cálcio foram significativamente reduzidos com o avanço da idade da folha. Folhas colhidas 15 dias após a completa expansão tiveram os teores reduzidos em $18,4 \%$, em comparação com os teores nas folhas colhidas com 5 dias de desenrolamento (Tabela 1). Assim, o consumo de folhas mais velhas é apropriado para pessoas sensíveis ao amargor e sabor adstringente causado pelas ráfides de oxalato de cálcio. As razões que levaram à queda dos teores de oxalato de cálcio, com o aumento da idade da folha, permanecem como objeto de estudo em trabalhos futuros.
Os níveis de açúcares solúveis totais foram diminuídos em $36 \%$ e o de amido em $86 \%$, com o envelhecimento das folhas de 5 para 15 dias (Tabela 1). O envelhecimento da folha foi acompanhado da diminuição do conteúdo de carboidratos não-estruturais. Nas primeiras horas após a colheita, verificouse um aumento na concentração dos açúcares solúveis, que se mostrou mais acentuado nas folhas colhidas com 5 e 8 dias após a completa expansão do limbo foliar. Em folhas coletadas nesses estádios, a elevação do conteúdo dos açúcares foi acompanhada por redução no nível de amido, seguindo-se de um período de estabilização dos seus teores até a completa senescência das folhas (Figura 1). Em folhas colhidas nos três estádios, houve contínuo consumo dos açúcares solúveis ao longo da senescência; isso sugere que os açúcares solúveis são uma das principais fontes de substrato do processo respiratório, enquanto que o amido parece contribuir como fonte de energia somente nos momentos inicias após a colheita, especialmente nas folhas mais novas (Figura 1). Em brócolos, foi também 


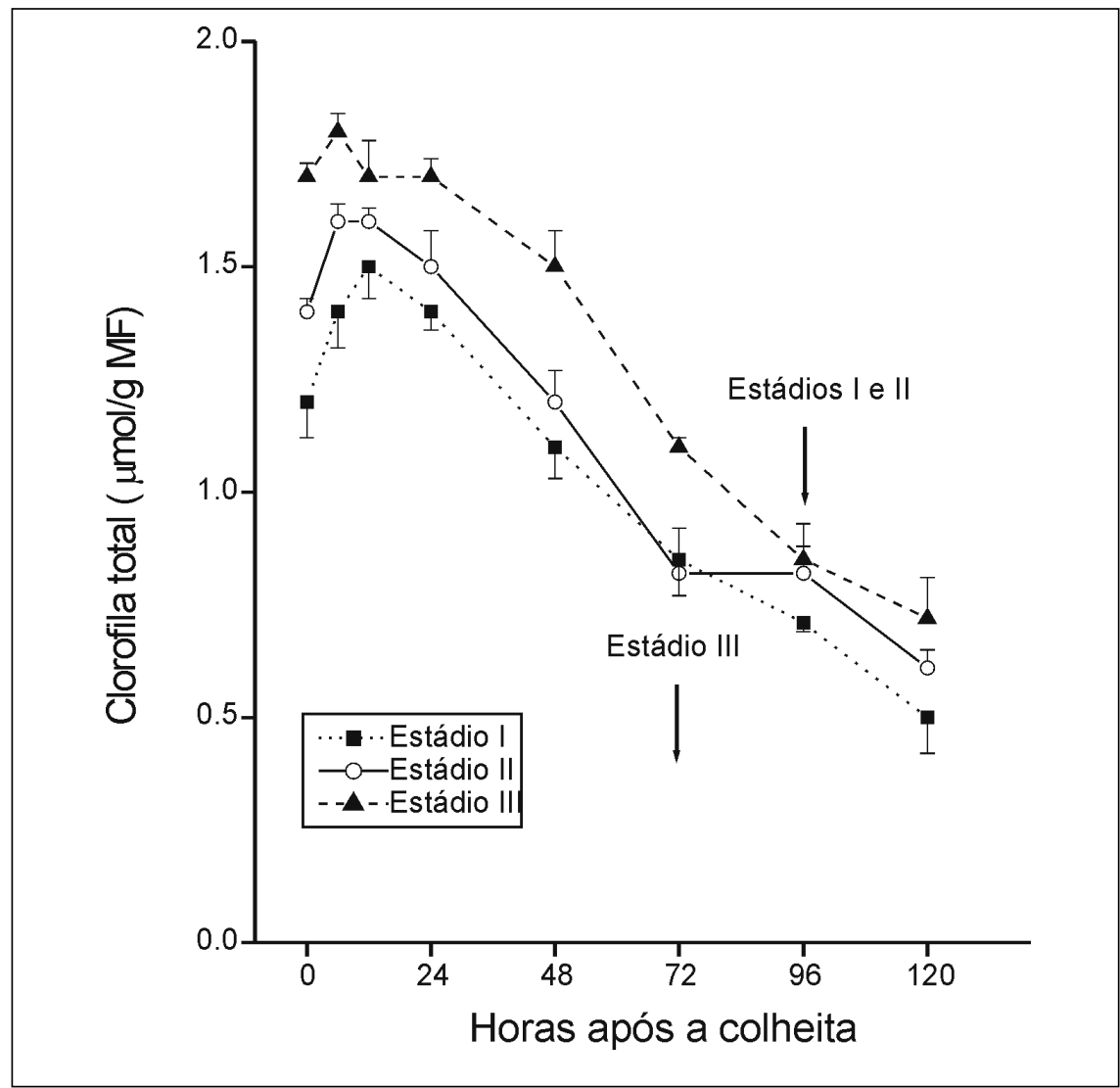

Figura 2. Alterações pós-colheita nos teores de clorofila total em folhas de taioba colhidas 5 (estádio I), 8 (estádio II) e 15 dias (estádio III) após a completa expansão dos respectivos limbos, e armazenadas a $25^{\circ} \mathrm{C}$ e $95 \%$ de umidade relativa. As setas indicam deterioração completa das folhas. Viçosa, UFV, 1998.

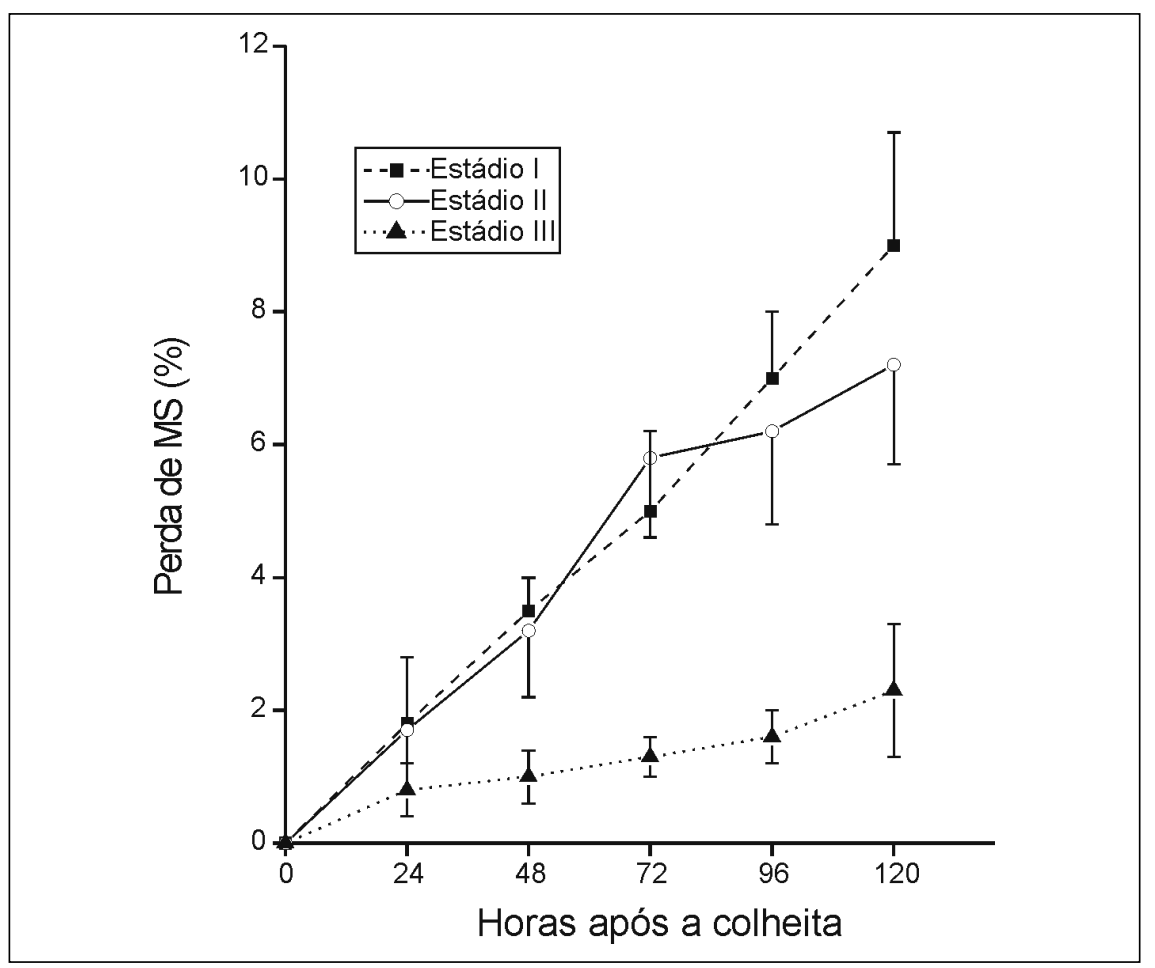

Figura 3. Perda acumulada de matéria fresca de folhas de taioba colhidas 5 (estádio I), 8 (estádio II) e 15 dias (estádio III) após completa expansão dos respectivos limbos, e armazenadas a $25^{\circ} \mathrm{C}$ e $95 \%$ de umidade relativa. Viçosa, UFV, 1998. encontrada uma tendência semelhante de redução dos açúcares totais ao longo da pós-colheita das inflorescências armazenadas em condições de temperatura ambiente (Finger et al., 1999).

O teor de clorofila total das folhas, no momento da colheita, mostrou-se maior com a idade pós-desenrolamento do limbo foliar. Nas primeiras horas após a colheita, ocorreu uma pequena elevação da clorofila total nas folhas coletadas nos três estádios (Figura 2), devido, possivelmente, à perda de matéria fresca por transpiração, resultando, portanto numa elevação da concentração da clorofila por unidade de matéria fresca. Thimann et al. (1982) sugeriram que isso pode ocorrer quase sempre que a folha é destacada da planta mãe, e deixada para senescer em condições de temperatura e umidade ambientes. Cerca de 24 horas após a colheita, iniciou-se um período de intensa degradação da clorofila até o completo amarelecimento das folhas (Figura 2). Resultados similares foram observados por outros autores ao analisarem a perda da cor verde em inflorescências de brócolos (King \& Morris, 1994) e em folhas de milho (Hung \& Kao, 1997). A partir de 48 horas após a colheita, as folhas coletadas no estádio III apresentavam sintomas iniciais de necrose foliar, que não foram exibidos nas folhas colhidas nos estádios I e II. As folhas colhidas nos estádios I e II foram consideradas não comercias 96 horas após a colheita, enquanto aquelas colhidas no estádio III foram descartadas 72 horas após a colheita (Figura 2). Esses resultados demonstram que folhas colhidas com 15 dias após a completa expansão do limbo foliar são menos apropriadas para o armazenamento à temperatura ambiente, devido ao amarelecimento precoce, em relação às folhas colhidas aos 5 e 8 dias da completa expansão do limbo foliar.

Folhas colhidas com 5 e 8 dias exibiram taxas de perda de matéria fresca significativamente superiores àquelas encontradas nas folhas colhidas com 15 dias (Figura 2). Após 96 horas, as folhas colhidas com 5 e 8 dias haviam perdido $7 \%$ e $6 \%$ de sua matéria fresca inicial, enquanto nas folhas colhidas com 15 dias essa perda foi de apenas 
$1,5 \%$ (Figura 3). As folhas mais velhas apresentaram maior resistência à desidratação, provavelmente devido a diferentes mecanismos associados a um aumento da resistência à transpiração, como espessamento da folha. Isso foi indicado pela redução da área foliar específica $\left(82 \mathrm{~cm}^{2} / \mathrm{g}\right.$ de matéria seca em folhas coletadas no estádio I, $80 \mathrm{~cm}^{2} / \mathrm{g}$ de matéria seca em folhas coletadas no estádio II e $77 \mathrm{~cm}^{2} / \mathrm{g}$ de matéria seca em folhas coletadas no estádio III) e, possivelmente também ao espessamento da cutícula.

\section{LITERATURA CITADA}

ARNON, D.I. Copper enzyme in isolated chloroplasts. Polyphenoloxidase in Beta vulgaris. Plant Physiology, v. 24, n. 1, p. 1-25, 1949.

BONDAR, G. Taro e taiobas. São Paulo: Melhoramentos, 1954. 32 p. (Boletim, 51).
CHAPMAN, T. A note on the measurement of leaf area of the tannia (Xanthosoma sagittifolium). Tropical Science, v. 41, n. 4, p. 351-352, 1964. FINGER, F.L.; ENDRES L.; MOSQUIM P.R.; PUIATTI M. Physiological changes during postharvest senescence of broccoli. Pesquisa Agropecuária Brasileira, Brasília, v. 34, n. 9, p. 1565-1569, 1999.

HUNG, K.T.; KAO C.H. Lipid peroxidation in relation to senescence of maize leaves. Journal of Plant Physiology, v. 150, n. 3, p. 283-286, 1997. HUSSAIN, M.; NORTON, G.; NEALA R.J. Composition and nutritive value of cormels of Colocasia esculenta (L.) Schott. Journal of Science and Food Agriculture, v. 35, n. 1, p. 11121119, 1984.

IWUOHA, C.I.; KALU, F.A. Calcium oxalate and physical-chemical properties of cocoyam (Colocasia esculenta and Xanthosoma sagittifolium) tuber flours as affected by processing. Food Chemistry, v. 54, n. 1, p. 51-56, 1995.

KAYS, S.J. Postharvest physiology of perishable plant products. New York: AVI Book, 1991, 532 p.
KING, G.A.; MORRIS, S.C. Early compositional changes during postharvest senescence of broccoli. Journal of the American Society for Horticultural Science, v. 119, n. 5, p. 1000-1005, 1994.

McCREADY, R.M.J.; GUGGOLZ, J.; SILVEIRA, V.; OWENS, H.H. Determination of starch and amylose in vegetables. Annals of Chemistry, v. 22, p. 1156-1158, 1950.

NETO, J.F. Manual de horticultura ecológica; guia de auto-suficiência em pequenos espaços. São Paulo: Nobel, 1995, 141 p.

RUBATZKY, V.E.; YAMAGUCHI, M. World vegetables: principles, production, and nutritive values. New York: Chapman \& Hall, 1997, 843 p.

THIMANN, K.V.; SATLER, S.O.; TRIPPI, V. Further extension of the syndrome of leaf senescence. In: Plant growth substances 1982. London, Academic Press, 1982, 683 p.

WILLS, R.; MCGLASSON, B.; GRAHAM, D. JOYCE, D. Postharvest - an introduction to the physiology \& handling of fruit, vegetables \& ornamentals. $4^{\text {th }}$ ed. Sydney: CAB International, 1998, $262 \mathrm{p}$. 